\title{
Waiting for PARIS-A Biological Target in Search of a Drug
}

\author{
PARIS farnesylation: Considerations in addressing a new \\ biological target for neuroprotection in patients with \\ Parkinson's disease
}

\author{
Richard K. Wyse ${ }^{\mathrm{a}, *}$, Simon R.W. Stott ${ }^{\mathrm{a}}$, Leah Mursaleen ${ }^{\mathrm{a}}$, Helen Matthews ${ }^{\mathrm{a}}$, \\ Valina L. Dawson ${ }^{\mathrm{b}, \mathrm{c}, \mathrm{d}, \mathrm{e}}$ and Ted M. Dawson ${ }^{\mathrm{b}, \mathrm{c}, \mathrm{e}, \mathrm{f}}$ \\ ${ }^{a}$ Cure Parkinson's, London, UK \\ ${ }^{\mathrm{b}}$ Neuroregeneration and Stem Cell Programs, Institute for Cell Engineering, Johns Hopkins University School \\ of Medicine, Baltimore, MD, USA \\ ${ }^{\mathrm{c}}$ Department of Neurology, Johns Hopkins University School of Medicine, Baltimore, MD, USA \\ ${ }^{\mathrm{d}}$ Department of Physiology, Johns Hopkins University School of Medicine, Baltimore, MD, USA \\ ${ }^{\mathrm{e}}$ Solomon H. Snyder Department of Neuroscience, Johns Hopkins University School of Medicine, Baltimore, \\ $M D, U S A$ \\ ${ }_{\mathrm{f}}^{\mathrm{f}}$ Department of Pharmacology and Molecular Sciences, Johns Hopkins University School of Medicine, Baltimore, \\ $M D, U S A$
}

Accepted 13 October 2021

Pre-press 4 November 2021

\begin{abstract}
A recent breakthrough paper published in Science Translational Medicine has provided compelling evidence that inhibition of Parkin Interacting Substrate (PARIS) may offer clinical researchers an important new therapeutic approach since it shows considerable promise as an important biological target potentially capable of pharmaceutical intervention to slow long term neurodegeneration in patients with Parkinson's disease (PD). We present several PD-relevant perspectives on this paper that were not discussed in that otherwise entirely scientific narrative. We also outline the some of the work leading up to it, including the massive drug screen that proved necessary to discover a clinically suitable inhibitor of PARIS (Farnesol), as well as relevant PD research within the wider drug class, issues surrounding its future formulation, and next steps in translating this new knowledge into the clinic to evaluate possible long-term PD patient benefits.
\end{abstract}

Keywords: Farnesol, PARIS, Parkin, PGC-1 $\alpha$, iLCT, neuroprotection, nanoformulation

\section{INTRODUCTION}

Few would deny the search for a cure for Parkinson's disease (PD) is a noble aim. Nobel prizes for

\footnotetext{
*Correspondence to: Richard Wyse, Cure Parkinson's, 120 New Cavendish Street, London W1W 6XX, UK. E-mail: richard@ cureparkinsons.org.uk.
}

literature were awarded to Pirandello (1934), Beckett (1969), and Pinter (2005); and the connections to PD here, are numerous. The central themes of Samuel Beckett's Waiting for Godot and Luigi Pirandello's Six Characters in Search of an Author both share uncertainty over pursuit of a clear direction, illogical progression, multiple interpretations, and 
lack of clarity about what is real, and what is not. That all sounds very much like the past 50 years of the search for fundamental new therapeutics for $\mathrm{PD}$, even despite it long remaining that noble aim. Harold Pinter was a close friend of Samuel Beckett. He was also president of the Pirandello society when he mentioned that, whilst rehearsing for the 1953 Paris premier of Godot, one of the actors noticed the hesitant cadence throughout a long monologue that Beckett had written into the voice of his character and, after speaking to a young doctor, Marthe Gautier, at the Pitié-Salpêtrière Hospital in Paris, she suggested Parkinson's disease. The actor immediately incorporated the disease into his portrayal, prompting Beckett at rehearsals to ask him why he was doing this? On learning the reason, Beckett admitted he hadn't even realized he had interwoven the disease into the character, but revealingly confided his mother had PD. Marthe, now 95, went on to become one of France's most celebrated and decorated doctors.

\section{INSIGHTS INTO A CRITICAL BIOCHEMICAL PROCESS}

Paris is a synonym of a great city of culture and cuisine, whilst PARIS is an acronym of 'Parkin Interacting Substrate'. Also known as zinc finger protein 746 (ZNF746), PARIS is a 644 amino acid protein member of the family of KRAB zinc-finger proteins transcriptional repressors [1]. It contains four zinc finger domains-which mediate sequencespecific DNA binding in the promoter region of target genes-and one KRAB domain that governs transcriptional repressor activity. Although PARIS has been reported to have functional roles in cancer cells [2-5], and in myoblast senescence [6], it was originally described as a key enzyme sitting mechanistically, between Parkin (an E3 ubiquitin ligase that mediates mitochondrial quality control [7-9]), and PGC- $1 \alpha$ (a transcriptional co-activator, peroxisome proliferator-activated receptor- $\gamma$ coactivator$1 \alpha$ which is a vital master regulator of mitochondrial size and number [10]). PARIS was first shown by Shin et al. to be centrally involved with the selective degeneration of dopaminergic neurons, and this effect was found to be reversible by either Parkin or PGC- $1 \alpha$ coexpression [11]. Siddiqui subsequently showed that mitochondrial quality control was PARIS-dependent in PD models in a manner requiring the lysosomal transcription factor EB (TFEB) [12]. PARIS inhibits both Parkin and PGC- $1 \alpha$ when its levels become raised, thereby accelerating dopaminergic cell loss. It has therefore been known for a decade that if a safe PARIS inhibitor could be identified then it would hold great clinical promise for patients with PD.

Very recently, a major breakthrough paper by Jo et al. has expanded our biological understanding of PARIS in the context of PD [13]. This study also involved a major drug screen and importantly reported the flavonoid, Farnesol, as an inhibitor of PARIS activity (Fig. 1); it appears to be a compound suitable for clinical evaluation to determine its disease-modifying potential in PD patients. We present here several PD-relevant perspectives on this paper, the work leading up to it, relevant PD research within the wider drug class, issues surrounding its formulation, and next steps in translating this new knowledge into the clinic to evaluate possible longterm PD patient benefits.

\section{PARIS EXPRESSION DRIVES PD NEURODEGENERATION}

Autosomal recessive genetic mutations in the ubiquitin E3 ligase, Parkin, can lower its activity and these patients typically present with an early-onset, slowly-progressive form of PD [14-16]. Even in idiopathic PD, however, normal levels of Parkin are also found to be aberrantly compromised [15, 17-18]. This is potentially important for all PD patients because, when Parkin levels decline for any reason, there is a resulting PARIS-dependent reduction of mitochondrial mass and respiration which leads to dopaminergic cell death [19] thereby accelerating the trajectory of their PD neurodegeneration. Consistent with this notion are the observations that, in a mouse model of age-related sporadic PD, oxidative reductions in Parkin solubility and activity are PARIS and PGC- $1 \alpha$ dependent [20]. PARIS also plays an important role in pathologic $\alpha$-synucleininduced degeneration because knockout of PARIS markedly attenuates the neurodegeneration set in motion by pathologic $\alpha$-synuclein [21]. Mutations in glucocerebrosidase, which are highly associated with the development of PD, leads to the accumulation of PARIS [22]. Moreover, PGC- $1 \alpha$ was shown to be a key-nodal point in the pathogenesis of PD as genes controlling cellular bioenergetics are reduced in PD patients [23]. The mitochondrial deficits caused when Parkin levels are low are triggered by defects in mitochondrial biogenesis that are propelled by the upregulation of PARIS which directly causes a 


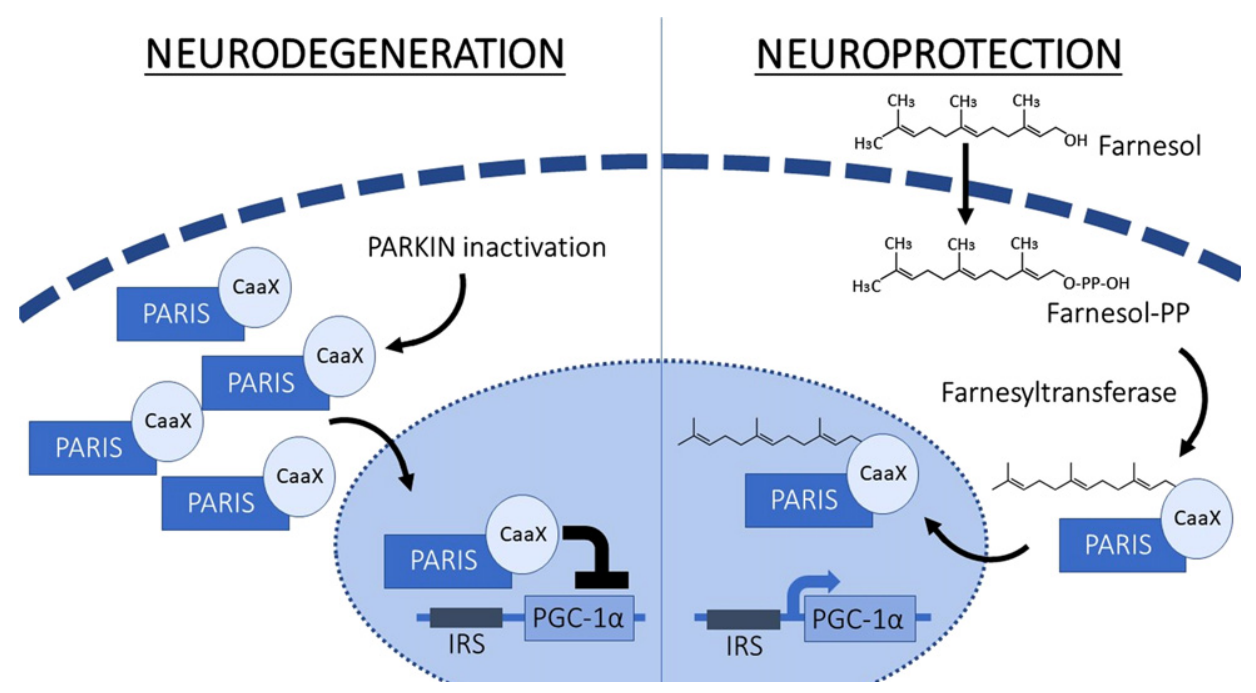

Fig. 1. In situations when Parkin is inactivated, or there is exposure to malformed fibrils of alpha synuclein, the level of PARIS increases, which directly leads to transcriptional suppression of PGC- $1 \alpha$, causing reduced mitochondrial function and thus furthering neurodegeneration. Farnesol however fosters the farnesylation of PARIS, thereby intercepting occupancy of PARIS on the PGC-1 $\alpha$ promoter which leads to higher levels of PGC-1 $\alpha$ and consequently promotes neuroprotection. IRS, insulin response sequences; Farnesyl-PP, Farnesyl diphosphate.

downregulation of PGC-1 $\alpha$ expression and thereby accelerates the loss of dopamine neurons [24, 25]. Further insight into this shows that when PARIS expression is knocked down in cellular models, this results in mitochondrial biogenesis, maintenance of mitochondrial membrane potential, improved respiration, and recovery of morphology and restoration of PGC- $1 \alpha$ expression. It is also interesting to note a recent report identifying genetic variants in the PARIS/ZNF746 gene that are significantly associated with early onset PD [26]. PARIS levels are also elevated in PD and thus measuring its levels could serve as a biomarker for the disease [27]. All of these observations conjoin to establish PARIS as a negative regulator of mitochondrial function [28] and authenticate that the Parkin-PARIS-PGC- $1 \alpha$ pathway occupies an important role in the progressive loss of dopaminergic neurons in PD.

\section{FINDING A CLINICALLY-SUITABLE INHIBITOR OF PARIS}

By 2011/2012, it was clear that if an inhibitor of PARIS could be identified, and if it was safe, then this might well offer a radically new therapeutic approach with potential to offer substantial diseasemodifying benefits in the long-term management of PD by fundamentally changing the trajectory of neurodegeneration, and unusually, it could be expedited via two different but simultaneous mechanisms, e.g., by increasing levels both of Parkin and PGC-1 $\alpha$. Since PARIS is a transcriptional repressor it is likely to regulate other genes. Overexpression of PARIS in mice leads to early lethality and selective loss of DA neurons [13]. The loss of DA neurons is rescued by overexpression of PGC- $1 \alpha$, while the early lethality is not rescued to a great extent. This indicates that PARIS has other targets. The identification and characterization of the extent of genes regulated by PARIS requires further study. PARIS knockout mice live a normal life span and do not have any substantial phenotype, suggesting that PARIS inhibitors would be well tolerated with minimal side effects [21]. Thus, PARIS activators might be expected to have on target effects, while PARIS inhibitors might have minimal side effects. Cure Parkinson's (CP), a global PD grant-giving charity, who founded the International PD Linked Clinical Trials initiative (iLCT), stepped forward and funded the major drug screen (>230,000 compounds) which has just successfully identified Farnesol as a PARIS inhibitor with properties suitable for oral dosing in humans [13]. As a group, CP regularly convenes a very large worldwide committee of PD experts who, over the past decade, have met to evaluate hundreds of candidate therapeutic approaches (including Farnesol) for their disease-modifying potential in PD and, so far, have gone on to foster $>20$ long-term disease-modifying trials in PD patients [29-31]. The wider backdrop here is that the therapeutic pipeline in the search for an 
authentic disease-modifying therapeutic has recently been rapidly expanding $[32,33]$, and while iLCT is centrally involved in many of these promising clinical initiatives, nevertheless we and others have long felt that finding a clinically safe inhibitor of PARIS could well become a major game-changer in PD.

The necessity of conducting a drug screen to find a PARIS inhibitor was a very unusual prerequisite for the iLCT PD drug development process. After all, the iLCT experience was that almost all the considerable number of individual biological targets of relevance to PD that the iLCT expert committee had already evaluated had typically started out with several drug candidates from which to choose to prosecute into clinical trials. However, in this particular case, no PARIS inhibitor had ever been identified. But, unlike Godot, Farnesol DID arrive [13]. However, it has taken an entire decade between the identification of the biological target, the identification of a safe PARIS inhibitor, and the current planning of the dosefinding and proof-of-concept clinical trials aimed to take this research to the next level. The drug screen had identified 7 candidates, but only 2 of these were practical to consider for clinical testing, with Farnesol representing the most appropriate to take forward into trials.

By the construct of the screening method, Farnesol was found to be highly effective in elevating PGC$1 \alpha$ levels even when PARIS levels were abnormally high and therefore compromising the intrinsic PGC$1 \alpha$ levels [13]. The potency of Farnesol in doing this was due to its ability to farnesylate PARIS via a posttranslational protein modification which attaches a small farnesyl group to carboxy-terminal cysteine sulphur on the PARIS protein, and thereby deactivating its physiologically inappropriate property of the transcriptional repression of PGC- $1 \alpha$. Additional in vivo studies in Parkin knockout and preformed alpha synuclein models of PD demonstrated that the protective nature of Farnesol worked extremely well [13]. The authors also interestingly showed the level of farnesylated PARIS was reduced in the substantia nigra of patients with PD, whilst levels were unaltered in the cortex.

\section{PD-RELEVANT PROPERTIES OF FARNESOL}

What do we know about Farnesol in relation to PD and other neurological conditions? The current poignant observation that Farnesol generates
PARIS farnesylation which, in turn, prevents PARIS occupancy on the PGC- $1 \alpha$ promoter (and which thereby beneficially increases the levels of PGC- $1 \alpha$ by reversing the PARIS mediated repression of its transcription) seems likely to offer advantageous neuroprotective mitochondrial and cellular consequences that should be tested without delay in long term clinical trials to assess its disease-modifying potential.

A PubMed search for research papers relating to Farnesol and PD retrieves only three [34-36]. All three focus on possible potent monoamine oxidase inhibitory properties of Farnesol in the context of cigarette smoke. That may not be totally irrelevant because, although farnesylation is clearly not involved here, might it be relevant that the monoamine oxidases are anatomically located adjacent to Parkin upon its translocation to the outer mitochondrial membrane of damaged mitochondria to induce mitophagy, and subsequent targeting for lysosomal disposal [37-39]?

Farnesol is classified as one of $>6000$ flavonoids derived from plants. It is a terpene alcohol found in corn, tomatoes, lemon grass, chamomile, peaches, and other vegetables and fruits. Its name originated from the acacia tree, Vachellia Farnesiana, which was grown for its perfume by Cardinal Farnese in Rome after its earlier importation from central America. Farnesol has been commercially produced from the flowers of this tree, and widely used in perfumery for $>300$ years.

Farnesol has never been clinically tested for any human disease. However, human exposure to Farnesol has been extensive worldwide via ingestion of various foods that contain it, and via inhalation in the context of cigarette smoking. Pre-clinical studies in PD models suggest those exposures are likely to be well below the dose needed to deactivate PARIS to the extent that this might generate tangible clinical benefits. It will therefore be crucial, before major clinical testing in PD patients, to determine what would be a safe and tolerable dose of Farnesol, and what are its pharmacokinetic properties? From this information, a suitable dosing regimen will hopefully be determined and Phase II clinical testing launched.

However, Farnesol is also attracting interest for tackling other neurological conditions and has already been shown to offer striking reductions in the severity of an immune response (autoimmune encephalomyelitis) in an experimental model of multiple sclerosis [40], a finding which could well lead to its clinical development for this condition. It is worth pointing out that those authors tentatively ascribe 
completely different biological actions of Farnesol to the beneficial response they have reported, including calcium channel inhibition, reduction of oxidative stress, attenuation of the inflammasome response, and lessening of pro-inflammatory cytokine secretion, some of which has previously been supported by others [41-46]. A decade earlier, an exceptionally thorough description of the large number of individual biochemical properties of Farnesol was reported by the NIH from the context of its potential clinical applications in oncology [47]. They particularly focused on how Farnesol also impacted on apoptosis, NF- $\kappa \mathrm{B}$ activation, inhibition of proliferation of tumour cells, induction of endoplasmic reticulum stress, induction of mitogen-activated protein kinase (MAPK), activation of peroxisome proliferatoractivated receptors (PPARs) amongst several other important intracellular processes. Now knowing that Farnesol, acting via repression of PARIS, is extremely effective in increasing PGC- $1 \alpha$ levels, then perhaps at least some of its properties as earlier reported [47] might well now be considered as downstream to the increase in mitochondrial size and number generated via that increased expression of PGC- $1 \alpha$.

Farnesyltransferase inhibitors have recently been shown to enhance $\alpha$-synuclein clearance by activating SNARE activity [48]. As such, Farnesol might be expected to interfere with SNARE activity via increased farnesyltransferase activity, thereby increasing the levels of $\alpha$-synuclein. However, Farnesol had the complete opposite effect where it reduced the accumulation of insoluble pathologic $\alpha$ synuclein while preventing the loss of DA neurons via farnesylation of PARIS in an in vivo pathologic $\alpha$-synuclein model of PD. These observations suggest that inhibiting PARIS and enhancing PGC$1 \alpha$ function can overcome any deleterious effect on SNARE activity and reduced $\alpha$-synuclein clearance. One may need to exercise caution with farnesyltransferase inhibitors, since farnesyltransferase levels are decreased in PD substantia nigra [13] and the use of farnesyltransferase inhibitors in PD could further increase the levels of PARIS and exacerbate the neurodegeneration.

\section{WHAT OTHER FLAVINOIDS MAY SHOW SIMILAR PD-RELEVANT PROPERTIES TO FARNESOL?}

Other flavonoids that are currently being considered for their potential therapeutic benefit in
PD include Kaempferol, Paenia Lactiflora, Curcurmin, Thymoquinone, Genistein, Safflower extract, Quercitin, Ginkgo Biloba, Icaritin, Honokiol, Luteolin, Baicalein, Ferulic Acid (amongst many others), and involve a wide range of proposed biochemical mechanisms [49-62]. A PubMed search on "parkinsons flavinoid" on October 10, 2021 produced 1,867 results, with $>100$ publications so far in 2021 . These papers report biological actions of relevance to $\mathrm{PD}$, and focus on a number of credible biological targets with theoretical potential to intercept neurodegeneration, notably in terms of reducing mitochondrial oxidative stress, Nrf2 activation, and inhibition of the inflammasome, but these are likely all downstream of the action of Farnesol on PARIS. Whilst Farnesol therefore may well also have some of these properties, it is structurally dissimilar from all those flavonoids mentioned above; in fact, we feel it unlikely that its properties of PARIS farnesylation will be shared by any of the other $6000+$ known flavonoids in this wide-ranging biological class.

\section{PURSUING FARNESOL INTO A LONG-TERM NEUROPROTECTIVE TRIAL IN PD PATIENTS}

Distilled from the 230,000 compounds in the drug screen as one of the top 7 positive hits for PARIS suppression, Farnesol has a relatively low molecular weight which will assist its transit across the blood brain barrier, and it has been specifically shown [13] to be effective against PARIS when given orally in PD models (including rescuing behavioral deficits). It has good ADME properties for clinical use, except that it is insoluble in water. There is currently very little information about what dose might be selected for use in PD trials and this key information will definitely have to be determined prior to the launch of any Phase II trial to test the disease-modifying potential that Farnesol may eventually offer PD patients. In Jo et al [13], the dose of Farnesol used in the mouse models was extremely high; mice were fed with $5 \mathrm{~g} / \mathrm{kg}$ Farnesol in chow for 7 days. Although this high dose resulted in a $37 \%$ increase in brain concentrations of Farnesol and enhanced PARIS farnesylation in mice, we emphasize that, at this stage, very little is known about its safety, or its efficacy, at ANY dose in humans. We strongly recommend that patients do not source Farnesol in any attempt to use it off-label. We are aware Farnesol is effective when applied topically to treat models of skin conditions, 
such as burns, but that Farnesol becomes cytotoxic in this context when used in high concentrations so, before testing in PD patients, it will be important to determine the oral dose of Farnesol that can be safely tolerated in humans, as well as to study its pharmacokinetic properties. If it turns out that Farnesol is safe and tolerable at a dose which inhibits PARIS then the Phase II neuroprotective trial will go ahead. Having said that, we also recognize that, since Farnesol has the potential to affect a large number of proteins in many tissues, direct modulation of PARIS itself might eventually turn out to be a better therapeutic approach here. For instance, antisense oligonucleotides or Protac approaches could be directed to selectively reduce PARIS levels. However, future investigations involving extensive pre-clinical and clinical research would be required to test these additional possibilities.

Given that Farnesol is hydrophobic, so cannot be dissolved in water, its safety in patients will need to be determined at whatever the most effective therapeutic dose might eventually turn out to be. Lumbar punctures will be needed to verify blood brain barrier penetrance. Thoughts immediately turn to what formulation might best support the dosing regimen. It might be possible to use a shaken suspension or to dissolve it in oil (although that might prove challenging to drink). It is unlikely to be well absorbed by the gut, but that also needs to be determined.

\section{REFORMULATION OF FARNESOL FOR CLINICAL TESTING IN PD PATIENTS}

A nanoformulation might offer improved gut absorption, and reduction of daily dose (and thereby, reduce any potential side effects IF present at the therapeutic dose that has most impact on PARIS inhibition). Lipid-based nanoparticles (such as liposomes and solid lipid nanoparticles) as well as polymerbased nanoparticles (such as micelles) have been developed to overcome the issues of poor solubility, stability, and bioavailability of antioxidant flavonoids, such as Farnesol and curcumin, to promote their utilization as potential disease therapeutics [63-67]. Lipid-based nanoparticles are considered the least toxic for drug delivery purposes since such nanoparticles are usually composed of naturally occurring molecules allowing for biocompatibility and biodegradability [68, 69]. Poly(lactic-co-glycolic acid) (PLGA) liposomes are FDA and EMA approved for use in vaccines and drug delivery and have already been used to formulate Farnesol for the treatment of fungal infections and were tested against the $C$. albicans microorganism. This initiative reported a nanoparticle size of $140 \mathrm{~nm}$ (which would be suitable for brain delivery) [67]. Similar liposome approaches have also been used for many other flavonoids (such as curcumin) and, in such formulations, have been shown to cross the blood-brain barrier readily reaching the cerebral cortex and the hippocampus [65].

Another nanoparticle approach that could be considered is to employ polymeric micelles. These are considered more advantageous for brain delivery due to characteristics such as small particle size $(10-200 \mathrm{~nm})$ within the ideal range for brain penetrance, high water-solubility as well as low toxicity $[69,70]$. Non-ionic surfactants such as pluronic F68 and labrasol are already used as excipients in numerous approved pharmaceuticals and have been used to formulate the flavonoids myricetin, quercetin, and fisetin into micelles for brain delivery [71]. Pluronics have also been used to formulate Farnesol and have been tested on Streptococcus mutans biofilms [72]. For many current nanocarrier delivery systems, the packing of lipophilic cations into the formulation can also be used to achieve mitochondria-targeted delivery [73-76] which may prove to be a highly appropriate approach for the prospective clinical use of Farnesol to inhibit PARIS to reduce PD neurodegeneration. Any nanoformulation approach, however, would likely require in vivo safety and pharmacokinetic data as well as testing in models of PD to ensure the therapeutic potential of Farnesol is retained before moving forward into clinical trials.

\section{CONCLUDING REMARKS}

This is an exciting time for the development of PD therapeutics aimed at slowing disease progression, with several highly promising biochemical targets currently being pursued both in and towards clinical testing. Seen through this encouraging prism, we hope the recent identification of a PARIS inhibitor will eventually make a major long term impact on the lives of PD patients and their families. Propelled by this new discovery [13], by the notion that Farnesol was recently described as a "Noble Unknown" [77] and, given the help Pirandello, Beckett and Pinter provided, we hope these great writers will peruse this article with interest from their own slices of writer's heaven in their long-term residences in Sicily, Montparnesse and Kensal Green. 


\section{CONFLICT OF INTEREST}

The co-authors (R.K.W, S.S, L.M. and HM), from Cure Parkinson's, a worldwide grant-giving medical charity, declare no conflicts of interest. T.M.D. and V.L.D are founders of Valted, LLC and hold an ownership equity interest in the company. These arrangements have been reviewed and approved by the Johns Hopkins University in accordance with its conflict of interest policies. T.M.D and V.L.D. are co-inventors on a patent related to this work, WO2017161155A1 "Methods for preventing or treating Parkinson's disease by the farnesylation of PARIS.” T.M.D. and V.L.D. are lead investigators on the recent Science Translational Medicine paper [13].

\section{REFERENCES}

[1] Cassandri M, Smirnov A, Novelli F, Pitolli C, Agostini M, Malewicz M, Melino G, Raschellà G (2017) Zinc-finger proteins in health and disease. Cell Death Discov 3, 17071.

[2] Jung JH, Jung DB, Kim H, Lee H, Kang SE, Srivastava SK, Yun M, Kim SH (2018) Zinc finger protein 746 promotes colorectal cancer progression via c-Myc stability mediated by glycogen synthase kinase 3beta and F-box and WD repeat domain-containing 7. Oncogene 37, 3715-3728.

[3] Chen YT, Yang CC, Shao PL, Huang CR, Yip HK (2019) Melatonin-mediated downregulation of ZNF746 suppresses bladder tumorigenesis mainly through inhibiting the AKTMMP-9 signaling pathway. J Pineal Res 66, e12536.

[4] Park WY, Lee HJ, Sim DY, Im E, Park JE, Ahn CH, Shim BS, Kim SH (2021) miR193a-5p mediated ZNF746 and cMyc signaling axis is critically involved in Morusin Induced apoptosis in colorectal cancer cells. Cells 10, 2065.

[5] Kim H, Lee JY, Park SJ, Kwag E, Koo O, Shin JH (2021) ZNF746/PARIS promotes the occurrence of hepatocellular carcinoma. Biochem Biophys Res Commun 563, 98-104.

[6] Bae JH, Jeong HJ, Kim H, Leem YE, Ryu D, Park SC, Lee YI, Cho SC, Kang JS (2020) ZNF746/PARIS overexpression induces cellular senescence through FoxO1/p21 axis activation in myoblasts. Cell Death Dis 11, 359.

[7] Clark IE, Dodson MW, Jiang C, Cao JH, Huh JR, Seol JH, Yoo SJ, Hay BA, Guo M (2006) Drosophila pink1 is required for mitochondrial function and interacts genetically with parkin. Nature 441, 1162-1166.

[8] Park JS, Davis RL, Sue CM (2018) Mitochondrial dysfunction in Parkinson's disease: New mechanistic insights and therapeutic perspectives. Curr Neurol Neurosci 18, 21.

[9] Ge P, Dawson VL, Dawson TM (2020) PINK1 and Parkin mitochondrial quality control: A source of regional vulnerability in Parkinson's disease. Mol Neurodegener 15, 20.

[10] Scarpulla RC (2011) Metabolic control of mitochondrial biogenesis through the PGC-1 family regulatory network. Biochim Biophys Acta 1813, 1269-1278.

[11] Shin J-H, Ko HS, Kang H, Lee Y, Lee Y-I, Pletinkova O, Troconso JC, Dawson VL, Dawson TM (2011) PARIS (ZNF746) repression of PGC-1 $\alpha$ contributes to neurodegeneration in Parkinson's disease. Cell 144, 689-702.

[12] Siddiqui A, Bhaumik D, Chinta SJ, Rane A, Rajagopalan S, Lieu CA, Lithgow GJ, Andersen JK (2015) Mitochondrial quality control via the PGC1 $\alpha$-TFEB signaling pathway Is compromised by Parkin Q311X mutation but independently restored by Rapamycin. J Neurosci 35, 1283312844.

[13] Jo A, Lee Y, Kam T-I, Kang S-U, Neifert S, Karuppagounder SS, Khang R, Kang H, Park H, Chou S-C, Oh S, Jiang H, Swing DA, Ham S, Pirooznia S, Umanah GKE, Mao X, Kumar M, Ko HS, Kang HC, Lee BD, Lee Y-I, Andrabi SA, Park C-H, Lee J-Y, Kim H, Kim H, Kim H, Cho JW, Paek SH, Na CH, Tessarollo L, Dawson VL, Dawson TM, Shin J-H (2021) PARIS farnesylation prevents neurodegeneration in models of Parkinson's disease. Sci Transl Med 13, eaax 8891.

[14] Kitada T, Asakawa S, Hattori N, Matsumine H, Yamamura Y, Minoshima S, Yokochi M, Mizuno Y, Shimizu N (1998) Mutations in the parkin gene cause autosomal recessive juvenile parkinsonism. Nature 392, 605-608.

[15] Panicker N, Dawson VL, Dawson TM (2017) Activation mechanisms of the E3 ubiquitin ligase PARKIN. Biochem $J$ 474, 3075-3086.

[16] Domingo A, Klein C (2018) Genetics of Parkinson disease. Handb Clin Neurol 147, 211-227.

[17] Dawson TM, Dawson VL (2014) PARKIN plays a role in sporadic Parkinson's disease. Neuro Degener Dis 13, 69-71.

[18] Kumar M, Acevedo-Cintrón J, Jhaldiyal A, Wang H, Andrabi SA, Eacker S, Karuppagounder SS, Brahmachari S, Chen R, Kim H, Ko HS, Dawson VL, Dawson TM (2020) Defects in mitochondrial biogenesis drive mitochondrial alterations in PARKIN-deficient human dopamine neurons. Stem Cell Rep 15, 629-645.

[19] Stevens DA, Lee Y, Kang HC, Lee BD, Lee YI, Bower A, Jiang H, Kang SU, Andrabi SA, Dawson VL, Shin J-H, Dawson TM (2015) PARKIN loss leads to PARISdependent declines in mitochondrial mass and respiration. Proc Natl Acad Sci U S A 112, 11696-11701.

[20] Siddiqui A, Rane A, Rajagopalan S, Chinta SJ, Andersen JK (2016) Detrimental effects of oxidative losses in parkin activity in a model of sporadic Parkinson's disease are attenuated by restoration of PGC1alpha. Neurobiol Dis 93,115-120.

[21] Brahmachari S, Lee S, Kim S, Yuan C, Karuppagounder SS, Ge P, Shi R, Kim EJ, Liu A, Kim D, Quintin S, Jiang H, Kumar M, Yun SP, Kam TI, Mao X, Lee Y, Swing DA, Tessarollo L, Ko HS, Dawson VL, Dawson TM (2019) Parkin interacting substrate zinc finger protein 746 is a pathological mediator in Parkinson's disease. Brain 142, 2380-2401.

[22] Bendikov-Bar I, Rapaport D, Larisch S, Horowitz M (2014) Parkin-mediated ubiquitination of mutant glucocerebrosidase leads to competition with its substrates PARIS and ARTS. Orphanet J Rare Dis 9, 86.

[23] Zheng B, Liao Z, Locascio JJ, Lesniak KA, Roderick SS, Watt ML, Eklund AC, Zhang-James Y, Kim PD, Hauser MA, Grünblatt E, Moran LB, Mandel SA, Riederer P, Miller RM, Federoff HJ, Wüllner U, Papapetropoulos S, Youdim MB, Cantuti-Castelvetri I, Young AB, Vance JM, Davis RL, Hedreen JC, Adler CH, Beach TG, Graeber MB, Middleton FA, Rochet JC, Scherzer CR; Global PD Gene Expression (GPEX) Consortium (2010) PGC-1 $\alpha$, a potential therapeutic target for early intervention in Parkinson's disease. Sci Transl Med 2, 52ra73.

[24] Pirooznia SK, Yuan C, Khan MR, Karuppagounder SS, Wang L, Xiong Y, Kang SU, Lee Y, Dawson VL, Dawson TM (2020) PARIS induced defects in mitochondrial biogenesis drive dopamine neuron loss under conditions of parkin or PINK1 deficiency. Mol Neurodegener 15, 17. 
[25] Lin CY, Huang YN, Fu RH, Liao YH, Kuo TY, Tsai CW (2020) Promotion of mitochondrial biogenesis via the regulation of PARIS and PGC-1alpha by parkin as a mechanism of neuroprotection by carnosic acid. Phytomedicine 2021 80, 153369.

[26] Li CY, Ou RW, Chen YP, Gu XJ, Wei QQ, Cao B, Zhang LY, Hou YB, Liu KC, Chen XP, Song W, Zhao B, Wu Y, Liu Y, Shang HF (2021) Genetic analysis of ZNF protein family members for early-onset Parkinson's disease in Chinese population. Mol Neurobiol 58, 3435-3442.

[27] Alieva AKh, Filatova EV, Karabanov AV, Illarioshkin SN, Slominsky PA, Shadrina MI (2015) Potential biomarkers of the earliest clinical stages of Parkinson's disease. Parkinsons Dis 2015, 294396.

[28] Mukherjee D, Chander V, Bandyopadhyay A (2020) PARIS-DJ-1 interaction regulates mitochondrial functions in cardiomyocytes, which is critically important in cardiac hypertrophy. Mol Cell Biol 41, e00106-20.

[29] Brundin P, Barker RA, Conn JP Dawson TM, Kieburtz K, Lees AJ, Schwarzschild MA, Tanner CM, Isaacs T, Duffen J, Matthews H, Wyse RKH (2013) Linked Clinical Trials the development of new clinical learning studies in Parkinson's disease using screening of multiple prospective new treatments. J Parkinsons Dis 3, 231-239.

[30] Brundin P, Wyse RK (2019) The Linked Clinical Trials initiative (LCT) for Parkinson's disease. Eur J Neurosci 49, 307-315.

[31] Stott SRW, Wyse RK, Brundin P (2021) Drug repurposing for Parkinson's disease: The International Linked Clinical Trials experience. Front Neurosci 15, 653377.

[32] McFarthing K, Buff S, Rafaloff G, Dominey T, Wyse RK, Stott SRW (2020) Parkinson's disease drug therapies in the clinical trial pipeline: 2020. J Parkinsons Dis 10, 757-774.

[33] McFarthing K, Rafaloff G, Baptista M, Wyse RK, Stott SRW (2021) Clinical trial highlights - Parkinson's disease drug therapies in the clinical trial pipeline: 2021 update. $J$ Parkinsons Dis 11, 891-903.

[34] Khalil AA, Davies B, Castagnoli Jr N (2006) Isolation and characterization of a monoamine oxidase B selective inhibitor from tobacco smoke. Bioorg Med Chem 14, 33923398.

[35] Budzianowski J (2013) Tobacco-once a medicinal plant. Does it contain substances with medicinal properties? Przegl Lek 70, 865-868.

[36] Sari Y, Khalil A (2015) Monoamine oxidase inhibitors extracted from tobacco smoke as neuroprotective factors for potential treatment of Parkinson's disease. Neurol Disord Drug Targets 14, 777-785.

[37] Cai Q, Zakaria HM, Simone A, Sheng Z-H (2012) Spatial parkin translocation and degradation of damaged mitochondria via mitophagy in live cortical neurons. Curr Biol 22, 545-552.

[38] Ugun-Klusek A, Theodosi TS, Fitzgerald JC, Burté F, Ufer C, Boocock DJ, Yu-Wai-Man P, Bedford L, Billett E (2019) Monoamine oxidase-A promotes protective autophagy in human SH-SY5Y neuroblastoma cells through Bcl-2 phosphorylation. Redox Biol 20, 167-181.

[39] Deol KK, Eyles SJ, Strieter ER (2020) Quantitative middledown MS analysis of Parkin-mediated ubiquitin chain assembly. J Am Soc Mass Spectrom 31, 1132-1139.

[40] Sell LB, Ramelow CC, Kohl HM, Hoffman K, Bains JK, Doyle WJ, Strawn KD, Hevrin T, Kirby TO, Gibson KM, Roullet J-B, Ochoa-Repáraz J (2021) Farnesol induces protection against murine CNS inflammatory demyelination and modifies gut microbiome. Clin Immunol, doi: 10.1016/j.clim.2021.108766.

[41] Roullet JB, Spaetgens RL, Burlingame T, Feng ZP, Zamponi GW (1999) Modulation of neuronal voltage-gated calcium channels by farnesol. J Biol Chem 274, 25439-25446.

[42] Santhanasabapathy R, Sudhandiran G (2015) Farnesol attenuates lipopolysaccharide-induced neurodegeneration in Swiss albino mice by regulating intrinsic apoptotic cascade. Brain Res 1620, 42-56.

[43] Gupta P, Sharma M, Arora N, Pruthi V, Poluri KM (2018) Chemistry and biology of farnesol and its derivatives: Quorum sensing molecules with immense therapeutic potential. Curr Top Med Chem 18, 1937-1954.

[44] Lee JH, Chinnathambi A, Alharbi SA, Shair OHM, Sethi G, Ahn KS (2019) Farnesol abrogates epithelial to mesenchymal transition process through regulating Akt/mTOR pathway. Pharmacol Res 150, 104504.

[45] Santos de Souza DS, Menezes-Filho JER, Santos-Miranda A, Jesus ICG, Neto JAS, Guatimosim S, Cruz JS, Vasconcelos CML (2019) Calcium overload-induced arrhythmia is suppressed by farnesol in rat heart. Eur J Pharmacol 859, 172488 .

[46] Souza DS, Barreto TO, Menezes-Filho JER, Heimfarth L, Rhana P, Rabelo TK, Santana MNS, Durço AO, Conceição MRL, Quintans-Júnior LJ, Guimarães AG, Cruz JS, Vasconcelos CML (2020) Myocardial hypertrophy is prevented by farnesol through oxidative stress and ERK1/2 signaling pathways. J Pharmacol 887, 173583.

[47] Joo JH, Jetten AM (2010) Molecular mechanisms involved in farnesol-induced apoptosis. Cancer Lett 287, 123-135.

[48] Cuddy LK, Wani WY, Morella ML, Pitcairn C, Tsutsumi K, Fredriksen K, Justman CJ, Grammatopoulos TN, Belur NR, Zunke F, Subramanian A, Affaneh A, Lansbury PT Jr, Mazzulli JR (2019) Stress-induced cellular clearance Is mediated by the SNARE protein ykt6 and disrupted by $\alpha$ synuclein. Neuron 104, 869-884.

[49] Silva Dos Santos J, Gonçalves Cirino JP, de Oliveira Carvalho P, Ortega MM (2021) The pharmacological action of kaempferol in central nervous system diseases: A review. Front Pharmacol 11, 565700.

[50] Du W, Liang X, Wang S, Lee P, Zhang Y (2020) The underlying mechanism of Paeonia lactiflora Pall. in Parkinson's disease based on a network pharmacology approach. Front Pharmacol 11, 581984.

[51] Abrahams S, Miller HC, Lombard C, van der Westhuizen FH, Bardien S (2021) Curcumin pre-treatment may protect against mitochondrial damage in LRRK2-mutant Parkinson's disease and healthy control fibroblasts. Biochem Biophys Rep 27, 101035.

[52] Dong J, Zhang X, Wang S, Xu C, Gao M, Liu S, Li X, Cheng N, Han Y, Wang X, Han Y (2021) Thymoquinone prevents dopaminergic neurodegeneration by attenuating oxidative stress via the Nrf2/ARE pathway. Front Pharmacol 11, 615598 .

[53] Alenzi F, Altamimi A, Kujan O, Tarakji B, Tamimi W, Bagader O, Al-Shangiti A, Talohi A, Alenezy A, Alswailmi F, Alenizi D, Salem M, Wyse, R (2013) Antioxidant properties of nigella sativa. J Mol Genet Med 7, 77.

[54] Du ZR, Gu Y, Xie XM, Zhang M, Jiang GY, Chen WF (2021) GPER and IGF-1R mediate the anti-inflammatory effect of genistein against lipopolysaccharide (LPS)-induced nigrostriatal injury in rats. J Steroid Biochem Mol Biol 214, 105989.

[55] Lei H, Ren R, Sun Y, Zhang K, Zhao X, Ablat N, Pu X (2020) Neuroprotective effects of safflower flavonoid extract in 
6-hydroxydopamine-induced model of Parkinson's disease may be related to its anti-inflammatory action. Molecules 25, 5206.

[56] Wang WW, Han R, He HJ, Li J, Chen SY, Gu Y, Xie C (2021) Administration of quercetin improves mitochondria quality control and protects the neurons in 6-OHDA-lesioned Parkinson's disease models. Aging (Albany NY) 13, 1173811751 .

[57] Kuang S, Yang L, Rao Z, Zhong Z, Li J, Zhong H, Dai L, Tang X (2018) Effects of ginkgo biloba extract on A53T alpha-synuclein transgenic mouse models of Parkinson's disease. Can J Neurol Sci 45, 182-187.

[58] Hao W, Xi L, Ze-Yu G, Ming L, Xin Z, Yi S, Xiao-Ping $P$ (2021) Icaritin provides neuroprotection in Parkinson's disease by attenuating neuroinflammation, oxidative stress, and energy deficiency. Antioxidants (Basel) 10, 529.

[59] Chen HH, Chang PC, Wey SP, Chen PM, Chen C, Chan MH (2018) Therapeutic effects of honokiol on motor impairment in hemiparkinsonian mice are associated with reversing neurodegeneration and targeting PPARgamma regulation. Biomed Pharmacother 108, 254-262.

[60] Siddique YH (2021) Role of luteolin in overcoming Parkinson's disease. Biofactors 47, 198-206.

[61] Chen M, Peng L, Gong P, Zheng X, Sun T, Zhang X, Huo J (2021) Baicalein mediates mitochondrial autophagy via miR-30b and the NIX/BNIP3 signaling pathway in Parkinson's disease. Biochem Res Int 2021, 2319412.

[62] Li X, Zhang J, Rong H, Zhang X, Dong M (2020) Ferulic acid ameliorates MPP(+)/MPTP-induced oxidative stress via ERK1/2-dependent Nrf2 activation: Translational implications for Parkinson disease treatment. Mol Neurobiol 57, 2981-2995.

[63] Ma Z, Haddadi A, Molavi O, Lavasanifar A, Lai R, Samuel JJ (2008) Micelles of poly(ethyleneoxide)-b-poly(epsiloncaprolactone) as vehicles for the solubilization, stabilization, and controlled delivery of curcumin. Biomed Mater Res A 86, 300-310.

[64] Tsai Y-M, Jan W-C, Chien C-F, Lee W-C, Lin L-C, Tsai T-H (2011) Optimised nano-formulation on the bioavailability of hydrophobic polyphenol, curcumin, in freely-moving rats. Food Chem 127, 918-925.

[65] Tsai Y-M, Chien C-F, Lin L-C, Tsai T-H (2011) Curcumin and its nano-formulation: The kinetics of tissue distribution and blood-brain barrier penetration. Int J Pharm 416, 331-338.

[66] Doggui S, Sahni JK, Arseneault M, Dao L, Ramassamy, C (2012) Neuronal uptake and neuroprotective effect of curcumin-loaded PLGA nanoparticles on the human SKN-SH cell line. J Alzheimers Dis 30, 377-392.

[67] Gürsu BY (2020) Potential antibiofilm activity of farnesolloaded poly(DL-lactide-co-glycolide) (PLGA) nanoparticles against Candida albicans. J Anal Sci Technol 11, 43.

[68] Ganesan P, Narayanasamy D (2017) Lipid nanoparticles: Different preparation techniques, characterization, hurdles, and strategies for the production of solid lipid nanoparticles and nanostructured lipid carriers for oral drug delivery. Sustain Chem Pharm 6, 37-56.

[69] Rakotoarisoa M, Angelova A (2018) Amphiphilic nanocarrier systems for curcumin delivery in neurodegenerative disorders. Medicines 5, 126.

[70] Elezaby RS, Gad HA, Metwally AA, Geneidi AS, Awad GA (2017) Self-assembled amphiphilic core-shell nanocarriers in line with the modern strategies for brain delivery. $J$ Control Release 261, 43-61.

[71] Wang G, Wang J, Guan R (2020) Novel phospholipid-based labrasol nanomicelles loaded flavonoids for oral delivery with enhanced penetration and anti-brain tumor efficiency. Curr Drug Deliv 17, 229-245.

[72] Mogen AB, Chen F, Ahn S-J, Burne RA, Wang D, Rice KC (2015) Pluronics-formulated farnesol promotes efficient killing and demonstrates novel interactions with streptococcus mutans biofilms. PLoS One 10, e0133886.

[73] Wang XX, Li Y-B, Yao H-J, Ju R-J, Zhang Y, Li R-J, Yu Y, Zhang L, Lu WL (2011) The use of mitochondrial targeting resveratrol liposomes modified with a dequalinium polyethylene glycol-distearoylphosphatidyl ethanolamine conjugate to induce apoptosis in resistant lung cancer cells. Biomaterials 32, 5673-5687.

[74] Bae Y, Jung MK, Lee S, Song SJ, Mun JY, Green ES, Han J, Ko KS, Choi JS (2018) Dequalinium-based functional nanosomes show increased mitochondria targeting and anticancer effect. Eur J Pharm Biopharm 124, 104-115.

[75] Mursaleen L, Noble B, Chan SHY, Somavarapu S, Zariwala MG (2020) N-Acetylcysteine nanocarriers protect against oxidative stress in a cellular model of Parkinson's disease. Antioxidants (Basel) 9,600.

[76] Mursaleen L, Somavarapu S, Zariwala MG (2020) Deferoxamine and curcumin loaded nanocarriers protect against rotenone-induced neurotoxicity. J Parkinsons Dis 10, 99-111.

[77] De Loof A, Schoofs L (2019) Mode of action of farnesol, the "Noble Unknown" in particular in Ca 2+homeostasis, and its juvenile hormone-esters in evolutionary retrospect. Front Neurosci 13, 141. 